\title{
STUDY OF LEFT VENTRICULAR DIASTOLIC DYSFUNCTION IN SYSTEMIC HYPERTENSION AND EVALUATION BY DOPPLER ECHOCARDIOGRAPHY
}

\author{
Hari Om Gupta1, Kuwer Devi Singh², Anuraag Gupta ${ }^{3}$,Manoj Indurkar
}

${ }_{1}^{1}$ Associate Professor, Department of Medicine, Sanjay Gandhi Memorial Hospital and Shyam Shah Medical College, Rewa. ${ }^{2}$ Assistant Professor, Department of Cardiology, Sanjay Gandhi Memorial Hospital and Shyam Shah Medical College, Rewa. 3Postgraduate Student, Department of Medicine, Sanjay Gandhi Memorial Hospital and Shyam Shah Medical College, Rewa. ${ }^{4}$ Professor and HOD, Department of Medicine, Sanjay Gandhi Memorial Hospital and Shyam Shah Medical College, Rewa.

\begin{tabular}{l}
\hline ABSTRACT \\
BACKGROUND \\
Persons suffering from Systemic Hypertension are likely to have cardiovascular side effects and this can be evaluated via a Doppler \\
Echocardiography. Hypertension has been shown to be a good prognostic marker in the cardiovascular mortality. This study was \\
done to detect the relationship between Hypertension and Left Ventricular Diastolic Dysfunction to evaluate its role in \\
pathogenesis and its influence amidst other factors such as gender, smoking, hypercholesterolaemia and effect of lifestyle.
\end{tabular}

\section{MATERIALS AND METHODS}

153 random patients presenting with or already having been diagnosed with systemic hypertension and not having any renal disease, diabetes mellitus, IHD, cardiomyopathy, valvular heart disease, pericardial disease etc. Consent was taken from all patients. History and examination was done according to a proforma. Blood pressure was taken along with haematological and biochemical examination and ECG was done to rule out secondary hypertension and IHD. All those in the inclusion criteria were taken for Echocardiography and M-mode measurements were taken and EF was calculated.

\section{RESULTS}

$55.6 \%$ were having diastolic dysfunction. Majority of them, i.e. 67 (72.8\%) of those having diastolic dysfunction were from age group of 51 - 60 years. Overweight patients, i.e. 52 (33.98\%) among which 27 (51.9\%) were having diastolic dysfunction. 64 patients $(41.8 \%)$ were having hypertension since 5 - 10 years, out of which $39(60.9 \%)$ were having diastolic dysfunction. There are 3 patients above 15 years history of hypertension and all had diastolic dysfunction.

\section{CONCLUSION}

Our study revealed that there is positive co-relation of duration of hypertension with diastolic dysfunction. Other contributory factors found were greater age, male sex, urban population, obesity and smoking which contributed to development of diastolic dysfunction.

\section{KEYWORDS}

Hypertension, Diastolic Dysfunction.

HOW TO CITE THIS ARTICLE: Gupta HO, Singh KD, Gupta A, et al. Study of left ventricular diastolic dysfunction in systemic hypertension and evaluation by Doppler echocardiography. J. Evolution Med. Dent. Sci. 2017;6(92):6593-6597, D0I: $10.14260 /$ jemds/2017/1429

\section{BACKGROUND}

The World Health Organisation attributes hypertension as the leading cause of cardiovascular morbidity and mortality ${ }^{1}$ and ranked third as a cause of disability-adjusted life-years. ${ }^{2}$ Nearly, one billion people are affected by hypertension worldwide and this figure is predicted to increase to 1.5 billion by 2025.3 The hypertension and cardiovascular disease burden is ever increasing globally. ${ }^{4}$ As estimated 17.3 million people, i.e. $30 \%$ of all global deaths are attributed to cardiovascular disease in 2008; in Indian scenario it is 29\% of all deaths. The earliest detectable consequence of hypertension is diastolic dysfunction. ${ }^{5}$

'Financial or Other Competing Interest': None.

Submission 18-10-2017, Peer Review 15-11-2017,

Acceptance 21-11-2017, Published 04-12-2017.

Corresponding Author:

Dr. Kuwer Devi Singh,

E-8 Doctors Colony,

Medical Campus,

Rewa-486001,

Madhya Pradesh.

E-mail: drkdsingh@gmail.com

DOI: $10.14260 /$ jemds/2017/1429
It may occur long before the systolic performance starts to fail and that is why in recent years LV diastolic dysfunction and its assessment have become a centre of attraction for many investigators. The presence of diastolic dysfunction is frequently overlooked in hypertensive patients. Hence, the data available on this subject is limited and becomes a compelling indication for our study.

This study stresses on the occurrence of diastolic dysfunction in hypertensive patients and also to identify and study the other factors associated with diastolic dysfunction such as age, gender, systolic and diastolic pressure, duration of hypertension, exercise and lifestyle.

\section{MATERIALS AND METHODS \\ Type of Study \\ Observational Study.}

\section{Duration of Study}

July 2016 to June 2017

Place of Study

Shyam Shah Medical College and Associated S. G. M. H, Rewa. 


\section{Sample Size}

This study was carried out on patients admitted to our hospital in Medicine wards from July 2016 to June 2017 (153 patients).

\section{Inclusion Criteria}

Patients with systemic hypertension.

\section{Exclusion Criteria}

- Renal disease.

- Diabetes mellitus.

- Ischaemic heart disease.

- Acute myocardial ischaemia.

- Chronic coronary heart disease.

- Cardiomyopathy (hypertrophic, infiltrative, restrictive).

- Valvular heart disease (Acute aortic or mitral regurgitation, Mitral stenosis, Aortic stenosis).

- Pericardial disease.

- Tamponade.

- Circulatory congestive states.

- Rapid fluid administration.

- Arteriovenous fistula.

- Severe anaemia.

- Thyrotoxicosis.

- $\quad$ Patients with congenital heart disease.

- Patients with LVEF is $<40 \%$.

- Coarctation of aorta, Vasculitis, Collagen vascular disease.

- Primary hyperaldosteronism, Cushing syndrome, Pheochromocytoma, Congenital adrenal hyperplasia.

- Neurogenic causes include the following: Brain tumour, Bulbar poliomyelitis, Intracranial hypertension.

- Drugs and toxins that cause hypertension include the following: Alcohol, Cocaine, Cyclosporine, tacrolimus, NSAIDs, Erythropoietin, Adrenergic medications, Decongestants containing ephedrine, Herbal remedies containing liquorice or ephedrine.

- Other causes include the following: Hyperthyroidism and hypothyroidism, Hypercalcaemia, Hyperparathyroidism, Acromegaly, Obstructive sleep apnoea, Pregnancyinduced hypertension.

A written informed consent was taken from all patients, complete history and clinical examination done according to a proforma. Duration of hypertension was taken as the period from the diagnosis of hypertension until the time of assessment. Blood pressure is the measure before echocardiography and then staging was done according to JNC VII guideline, blood pressure was measured as a mean of two readings recorded on the right arm, measured under standardised conditions with the participant seated (after 5 mins rest).

Then patients were subjected to detailed clinical examination, routine haematological and biochemical examination and ECG was done to rule out secondary hypertension and IHD.

All those included for study were subjected for echocardiography and colour Doppler. Analysis was performed by using PHILIPS HD-7 and following parameters were measured: M-Mode measurements were taken, ejection fraction $(\mathrm{EF})$ and other parameters were taken.

\section{Statistical Analysis}

Data was collected and analysed via Chi-square test to assess the categorical data presented as numbers and percentages. $\mathrm{P}$ value of 0.05 or less was considered statistically significant.

\section{RESULTS}

\begin{tabular}{|c|c|c|c|}
\hline $\begin{array}{c}\text { Diastolic } \\
\text { Dysfunction }\end{array}$ & Present & Absent & Total \\
\hline No. of Patients & $85(55.55 \%)$ & $68(44.45 \%)$ & 153 \\
\hline \multicolumn{3}{|c|}{ Table 1. Distribution of Patients with Respect to } \\
Hypertension and occurrence of Diastolic Dysfunction \\
\hline
\end{tabular}

Out of a total of 153 patients, 85 (55.5\%) had diastolic dysfunction.

\begin{tabular}{|c|c|c|c|}
\hline \multirow{2}{*}{ Gender } & \multicolumn{2}{|c|}{ Diastolic Dysfunction } & \multirow{2}{*}{ Total } \\
\cline { 2 - 3 } & Present & Absent & \\
\hline Male & $49(57.6 \%)$ & $36(42.4 \%)$ & 85 \\
\hline Female & $36(52.9 \%)$ & $32(47.1 \%)$ & 68 \\
\hline Table 2. Diastolic Dysfunction and Gender Distribution \\
\hline
\end{tabular}

85 were males and 68 were females; 49 males i.e. $57.6 \%$ had diastolic dysfunction, while 36 females i.e. $52.9 \%$ had diastolic dysfunction.

Chi-square $=0.3388, \mathrm{P}$ value $=0.6757$ and hence it is not significant.

\begin{tabular}{|c|c|c|c|}
\hline Age Group & \multicolumn{2}{|c|}{ Diastolic Dysfunction } & \multirow{2}{*}{ Total } \\
\hline & Present & Absent & \\
\hline $31-40$ & $6(31.5 \%)$ & $13(68.5 \%)$ & 19 \\
\hline $41-50$ & $12(28.5 \%)$ & $30(71.43 \%)$ & 42 \\
\hline $51-60$ & $67(72.8 \%)$ & $25(27.2 \%)$ & 92 \\
\hline Table 3. Distribution of Patients with Respect to Age Group
\end{tabular}

Most patients belonged to age group of 51 - 60, i.e. 92 patients and had the maximum number of patients with diastolic dysfunction.

Chi-square- 27.923, $\mathrm{P}$ value $<0.0001$ and hence there is significant co-relation between age group and increasing chance of diastolic dysfunction.

\begin{tabular}{|c|c|c|c|}
\hline \multirow{2}{*}{ Population } & \multicolumn{2}{|c|}{ Diastolic Dysfunction } & \multirow{2}{*}{ Total } \\
\cline { 2 - 3 } & Present & Absent & \\
\hline Rural & $26(41.9 \%)$ & $36(58.1 \%)$ & 62 \\
\hline Urban & $59(64.8 \%)$ & $32(35.2 \%)$ & 91 \\
\hline $\begin{array}{c}\text { Table 4. Diastolic Dysfunction with Respect to Area of } \\
\text { Population and occurrence of Diastolic Dysfunction }\end{array}$ \\
\hline
\end{tabular}

Majority of patients, 91 (59.4\%) were from urban areas where $59(64.8 \%)$ were having diastolic dysfunction.

Among the 153 patients $62(40.5 \%)$ were from rural areas, where $36(58.1 \%)$ were found to be normal.

Chi-square $=7.832, \quad \mathrm{P}$ value $=0.0051$ and there is significant co-relation between area of population and diastolic dysfunction. 


\begin{tabular}{|c|c|c|c|}
\hline $\begin{array}{c}\text { Duration of } \\
\text { Hypertension } \\
\text { (In Years) }\end{array}$ & \multicolumn{2}{|c|}{ Diastolic Dysfunction } & \multirow{2}{*}{ Total } \\
\cline { 2 - 3 } & Present & Absent & \\
\hline$\leq 1$ & $6(40 \%)$ & $9(60 \%)$ & 15 \\
\hline $1-5$ & $22(41.5 \%)$ & $31(58.5 \%)$ & 53 \\
\hline $5-10$ & $39(60.9 \%)$ & $25(39.1 \%)$ & 64 \\
\hline $10-15$ & $15(83.33 \%)$ & $3(16.67 \%)$ & 18 \\
\hline$>15$ & $3(100 \%)$ & $0(0 \%)$ & 3 \\
\hline \multicolumn{3}{|c|}{ Table 5. Diastolic Dysfunction with Respect to } \\
Duration of Hypertension \\
\hline
\end{tabular}

Among the 153 patients 64 (41.83\%) were having hypertension since 5 - 10 years, out of which 39 (60.9\%) were having diastolic dysfunction. There are 3 patients above 15 years of history of hypertension, all of whom are having diastolic dysfunction.

Chi-square $=14.481, \mathrm{P}$ value is 0.0059 and hence there is a significant co-relation between duration of hypertension and prevalence of diastolic dysfunction.

\begin{tabular}{|c|c|c|c|}
\hline \multirow{2}{*}{$\begin{array}{c}\text { Group of } \\
\text { Drugs }\end{array}$} & Diastolic Dysfunction & \multirow{2}{*}{ Total } \\
\cline { 2 - 3 } & Present & Absent & \\
\hline ACE I & $2(66.6 \%)$ & $1(44.4 \%)$ & 3 \\
\hline Alfa AGO + D & $12(70.6 \%)$ & $5(29.42 \%)$ & 17 \\
\hline ARB & $13(41.9 \%)$ & $18(58.1 \%)$ & 31 \\
\hline ARB + H & $11(42.3 \%)$ & $15(57.7 \%)$ & 26 \\
\hline Beta Blockers & $9(90 \%)$ & $1(10 \%)$ & 10 \\
\hline CC Blockers & $10(55.5 \%)$ & $8(44.45 \%)$ & 18 \\
\hline $\begin{array}{c}\text { ACE I + Beta } \\
\text { Blockers }\end{array}$ & $10(71.4 \%)$ & $4(28.6 \%)$ & 14 \\
\hline $\begin{array}{c}\text { ACE I + CC } \\
\text { Blockers }\end{array}$ & $7(70 \%)$ & $3(30 \%)$ & 10 \\
\hline $\begin{array}{c}\text { ARB + Beta } \\
\text { Blockers }\end{array}$ & $4(57.14 \%)$ & $3(32.86 \%)$ & 7 \\
\hline $\begin{array}{c}\text { ARB + CC } \\
\text { Blockers }\end{array}$ & $5(55.5 \%)$ & $9(44.5 \%)$ & 14 \\
\hline $\begin{array}{c}\text { Beta Blockers } \\
+ \text { CC Blockers }\end{array}$ & $2(66.7 \%)$ & $1(33.3 \%)$ & 3 \\
\hline \multicolumn{3}{|c|}{ Table 6. Diastolic Dysfunction with } \\
\hline \multicolumn{4}{|c|}{ Respect to Group of Drugs } \\
\hline
\end{tabular}

ACE I= Angiotensin Converting Enzyme Inhibitor.

Alfa AGO $+\mathrm{D}=$ Alfa agonist and Diuretic.

$\mathrm{ARB}=$ Angiotensin Receptor Blocker.

$\mathrm{ARB}+\mathrm{H}=$ Angiotensin Receptor Blocker + Hydrochlorothiazide.

CC Blockers $=$ Calcium Channel Blockers.

Among the 31 patients taking ARB 18 (58.1\%) were found to be normal, while 26 on ARB $+\mathrm{H}(57.7 \%)$ were normal. Out of 18 on CC blockers, 10 (55.5\%) were having diastolic dysfunction.

\begin{tabular}{|c|c|c|c|}
\hline \multirow{2}{*}{ Type of Lifestyle } & \multicolumn{2}{|c|}{ Diastolic Dysfunction } & \multirow{2}{*}{ Total } \\
\cline { 2 - 3 } & Present & Absent & \\
\hline Sedentary & $57(76.5 \%)$ & $18(23.5 \%)$ & 75 \\
\hline Moderate & $19(35.8 \%)$ & $34(64.2 \%)$ & 53 \\
\hline Vigorous & $9(36 \%)$ & $16(64 \%)$ & 25 \\
\hline Table 7. Diastolic Dysfunction and Type of Lifestyle \\
\hline
\end{tabular}

Majority of patients, 75 (49\%) were having sedentary lifestyle and 57 (76.5\%) were having diastolic dysfunction.

Chi-square $=24.904, \mathrm{P}$ value $<0.05$ and therefore there is significant association with type of lifestyle and presence of diastolic dysfunction.

\begin{tabular}{|c|c|c|c|}
\hline \multirow{2}{*}{$\begin{array}{c}\text { Cholesterol } \\
\text { Group }\end{array}$} & \multicolumn{2}{|c|}{ Diastolic Dysfunction } & \multirow{2}{*}{ Total } \\
\cline { 2 - 3 } & Present & Absent & \\
\hline$<200$ (desirable) & $37(44.04 \%)$ & $47(55.9 \%)$ & 84 \\
\hline $\begin{array}{c}200-239 \\
\text { (borderline high } \\
\text { risk) }\end{array}$ & $17(54.83 \%)$ & $14(45.17 \%)$ & 31 \\
\hline$\geq 240$ (high risk) & $31(81.57 \%)$ & $7(18.43 \%)$ & 38 \\
\hline \multicolumn{2}{|c|}{ Table 8. Diastolic Dysfunction and Cholesterol Levels } \\
\hline
\end{tabular}

Out of 84 patients with desirable cholesterol levels, 47 (55.96\%) were having normal diastolic function and out of 38 patients with high risk cholesterol levels 31 (81.57\%) were having abnormal diastolic function.

Chi-square $=14.934, \mathrm{P}$ value is 0.0006 and therefore there is significant association with cholesterol levels and presence of diastolic dysfunction.

\begin{tabular}{|c|c|c|c|}
\hline Smoking & \multicolumn{2}{|c|}{ Diastolic Dysfunction } & Total \\
\hline & Present & Absent & \\
\hline Yes & $44(77.19 \%)$ & $13(22.81 \%)$ & 57 \\
\hline No & $41(42.7 \%)$ & $55(57.3 \%)$ & 96 \\
\hline Type 9. Diastolic Dysfunction and Effect of Smoking \\
\hline
\end{tabular}

Majority of patients, i.e. $96(62.7 \%)$ were non-smokers, $55(57.3 \%)$ were found to be normal. In 57 (37.3\%) smokers, 44 (77.19\%) were having diastolic dysfunction.

Chi-square $=17.225$, $\mathrm{P}$ value is $<0.0001$ and hence there is significant association with smoking and the presence of diastolic dysfunction.

\section{DISCUSSION}

Out of 153 patients of hypertension which we have screened, 85 (55.55\%) were found to having abnormal diastolic function.

In 2006, Ike and VO Ikeh et al in study population of 69 males and 71 females found that prevalence of diastolic dysfunction in the hypertensive groups in this study was $82.86 \% .^{6}$ Majority, i.e. 67 (78.8\%) of the patients of diastolic dysfunction were from the age group of $51-60$ years out of 153 patients. Similar to this Margaret M Redfield and Steven J Jacobsen et al in 2003, cross-sectional survey found that out of 502 patients with diastolic dysfunction 272 were above 65 years. ${ }^{7}$

In our study, out of 85 patients having diastolic dysfunction, 49 (57.6\%) were males and 36 (42.4\%) were females. Same results were found by Rolf Wachter and Claus Lüers et al in 2007. In their study, 439 hypertensive patients were selected for participation in this study. Sex-specific analysis revealed that diastolic function was mainly limited to the male subgroup. ${ }^{8}$

Majority of patients, 91 (59.4\%) were from urban areas out of which 59 (64.8\%) were having diastolic dysfunction. Among the 153 patients $62(40.5 \%)$ were from rural areas, out of which $36(58.1 \%)$ were found to be normal. These may be because of difference in lifestyle in rural and urban population. Rural population has less sedentary lifestyle than urban population. Though, this needs further evaluation.

Among the 153 patients $64(41.8 \%)$ were having hypertension since 5 - 10 years, out of which 39 (60.9\%) were having diastolic dysfunction. There are 3 patients above 15 years of history of hypertension, all of them are having diastolic dysfunction. As the duration of hypertension increases, incidence of diastolic dysfunction increases. 
Leslie W Miller and Emil D Missov in 2001, the duration of hypertension seemed to play a role in the development of diastolic dysfunction. Looking at the data, one may find it peculiar to have patients with less than 8 years history of hypertension have higher incidence of developing diastolic dysfunction (Refer interpretation of results). This may contradict the fact that patients with longer history of hypertension tend to have higher incidence of diastolic dysfunction. ${ }^{9}$

Majority of patients 96 (62.7\%) were non-smokers, 55 (57.3\%) were found to be normal. In 57 (37.25\%) smokers, 44 (77.19\%) were having diastolic dysfunction. In 2006 Osman Karakaya and Irfan Barutcu et al, thirty chronic smokers underwent a complete transthoracic echocardiographic examination found that acute cigarette smoking impaired both left and right ventricular diastolic function in chronic smokers. ${ }^{10}$ Majority of patients, 75 (49\%) were having sedentary lifestyle and 57 (76.5\%) were having diastolic dysfunction.

Louse Bennet and Charlote Larsson et al studied men and women of 30 - 75 years of age were consecutively invited for conventional echocardiography and tissue velocity imaging (n-1149). Structured questionnaires and physical examinations were conducted using standardised methods. Sedentary leisure time physical activity is independently associated with DD in females. Identification of a sedentary lifestyle in females increases the probability of diagnosing DD. 11

Out of 84 patients with desirable cholesterol levels 47 (55.96\%) were having normal diastolic function and out of 38 patients with high-risk cholesterol levels 31 (81.57\%) were having abnormal diastolic function.

Pasquale Palmiero and Maria Maiello et al in 2002 in a total of 200 consecutive postmenopausal women (mean age $47.5 \pm 4$ years) with mild-to-moderate hypertension were studied, in women with mild-to-moderate hypertension, high total cholesterol levels and low HDL levels are associated with impaired diastolic function. ${ }^{12}$ Among the 31 (20.2\%) patients on ARBs 18 (58.1\%) were found to be normal, similarly 26 on ARBS+ H, 16 (57.7\%) were normal. Out of 10 on blockers, 7 (70\%) were having diastolic dysfunction. In combination, out of 7 who were on ARB + CC blockers $3(32.86 \%)$ were normal, 3 on Beta blockers + CC blockers, of which $2(66.67 \%)$ were having diastolic dysfunction.

In our study we found ARB and ARB $+\mathrm{H}$ are much effective antihypertensive than others, and in combination ARBs and Calcium channel blockers are more effective than others.

Williams B and Lacy PS et al in 2006 recruited 2199 patients in 5 ASCOT centres found that optimal blood pressure reduction using agents such as diuretics, calcium antagonists and RAAS antagonists can reduce CV-related morbidity and mortality and is associated with enhanced myocardial relaxation, reduced central aortic stiffness and a dramatic reduction in the incidence of heart failure. ${ }^{13}$

\section{CONCLUSION}

- $\quad$ Based on the result of our study, we found that age was one of the factors that contribute to the development of diastolic dysfunction.
- This study showed that males have significant association with the development of diastolic dysfunction in hypertensive patients.

- Our study suggests that urban population is more susceptible for diastolic dysfunction as compared to rural population.

- In this study, obese population is more susceptible for the development of diastolic dysfunction.

- As the duration of hypertension increases, incidence of diastolic dysfunction increases. The patients with longer history of hypertension tend to have higher incidence of diastolic dysfunction.

- The diastolic function of the heart was found to be impaired among smokers.

- In this study, a sedentary lifestyle is associated with a decline of ventricular compliance.

- In our study, we found that hypercholesterolaemia that is more than $240 \mathrm{mg} / \mathrm{dL}$ serves as a predictor for the development of diastolic dysfunction.

- In this study, we found that angiotensin receptor blockers alone or with hydrochlorothiazide or with calcium channel blockers were more effective antihypertensive with respect to diastolic function.

\section{REFERENCES}

[1] Chockalingam A. World hypertension day and global awareness. Can J Cardiol 2008;24(6):441-4.

[2] Ezzati M, Lopez AD, Rodgers A, et al. Selected major risk factors and global and regional burden of disease. Lancet 2002;360(9343):1347-60.

[3] Chockalingam A. Impact of world hypertension day. Can J Cardiol 2007;23(7):517-9.

[4] Reddy KS, Yusuf S. Emerging epidemic of cardiovascular disease in developing countries. Circulation 1998;97(6):596-601.

[5] Izzo JL, Grandman AH. Mechanisms and management of hypertensive heart disease: from left ventricular hypertrophy to heart failure. Med Clin $\mathrm{N}$ Am 2004;88(5):1257-71.

[6] Ike S, Ikeh V. The prevalence of diastolic dysfunction in adult hypertensive nigerians. Ghana Med J 2006;40(2):55-60.

[7] Redfield MM, Jacobsen SJ, Burnett JC, et al. Burden of systolic and diastolic ventricular dysfunction in the community: appreciating the scope of the heart failure epidemic. JAMA 2003;289(2):194-202.

[8] Wachter R, Lüers C, Kleta S, et al. Impact of diabetes on left ventricular diastolic function in patients with arterial hypertension. Eur J Heart Fail 2007;9(5):46976.

[9] Miller LW, Missov ED. Epidemiology of heary failure. Cardiology Clinics 2001;19(4):547-55.

[10] Karakaya O, Barutcu I, Esen AM, et al. Acute smokinginduced alterations in doppler echocardiographic measurements in chronic smokers. Tex Heart Inst J 2006;33(2):134-8.

[11] Bennet L, Larsson C, Söderström M, et al. Diastolic dysfunction is associated with sedentary leisure time physical activity and smoking in females only. Scand J Prim Health Care 2010;28(3):172-8. 
[12] Palmiero P, Maiello M, Passantino A, et al. Correlation between diastolic impairment and lipid metabolism in mild-to-moderate hypertensive postmenopausal women. Am J Hypertension 2002;15(7):615-20.
[13] Williams B, Lacy PS, Thom SM, et al. Differential impact of blood pressure lowering drugs on central aortic pressure and clinical outcomes: principal results of the conduit artery function evaluation (CAFE) study. Circulation 2006;113(9):1213-25. 